\title{
UMA ANÁLISE DE DIFERENTES QUESTÕES RELACIONADAS AO DESENVOLVIMENTO SUSTENTÁVEL NA ONTEMPORANEIDADE
}

\author{
AN ANALYSIS OF DIFFERENT SUBJECTS RELATED TO THE \\ MAINTAINABLE DEVELOPMENT

\section{UN ANÁLISIS DE DIVERSAS CUESTIONES RELATIVAS AL DESARROLLO SOSTENIBLE EN CONTEMPORÁNEO}

\author{
Maria Socorro Duarte da Silva Couto \\ Doutora em Ciências Ambientais (UFG) e Professora do Instituto Federal de \\ Educação, Ciências e Tecnologia de Goiás - Campus Inhumas. \\ Email:socorrodc@inhumas.ifgo.edu.br \\ Renato Araújo Teixeira \\ Doutorando em Geografia pelo IESA/UFG \\ Professor do Instituto Federal de Educação, Ciências e \\ Tecnologia de Goiás - Campus Inhumas. \\ E-mail: renatoaraujoufg@ yahoo.com.br \\ renato@inhumas.ifgo.edu.br
}

\begin{abstract}
Resumo
De todas as civilizações que já existiram na história da humanidade, nenhuma outra degradou tanto o meio ambiente como a sociedade contemporânea, em virtude dela estar fundamentada em modelos de desenvolvimento econômico que visam somente o lucro em detrimento do meio natural e social. Nesse contexto, surge o modelo de desenvolvimento sustentável, que exige uma ação global no sentido de reformular todo o modelo de sociedade industrial, permitindo harmonizar a relação do homem com a natureza e as relações dos homens entre si. Hoje, o discurso ambiental tem se intensificado e ganho importância, principalmente, na formulação de políticas, modelos e teorias a respeito de desenvolvimento, apoiado na concepção de desenvolvimento sustentável. Neste artigo é feita uma síntese sobre os impasses provocados pela implantação do modelo de desenvolvimento sustentável, além de uma análise de diferentes questões relacionadas a esse modelo de desenvolvimento, que provoca opiniões contraditórias acerca dos "sacrifícios" sociais e individuais decorrentes de uma atitude mais consciente e equilibrada em relação ao uso dos recursos naturais.
\end{abstract}

Palavras-chave: desenvolvimento sustentável, meio ambiente, sociedade contemporânea, industrialização. 


\begin{abstract}
From all civilizations in the history, none of them have caused so much impact to the environment like the contemporary society. Unlike the traditional economic development model, which aims the profit against the natural and social environment, comes out the sustainable development model, which requires a global action for reformulating the industrial society. This change can allow the harmonization between the human been and the nature. Today, the environmental discourse has been intensified and gain importance in the formulation of development policies. In this article we made an analysis of different subjects related to that sustainable development model, which invokes contradictory opinions concerning the social and individual "loss" in relation to the use of natural resources.
\end{abstract}

Keywords: sustainable development, environment, contemporary society, industrialization.

\title{
Resumen
}

De todas las civilizaciones que han existido en la historia humana, ninguna otra há degradado tanto el medio ambiente como la sociedad contemporánea, en virtud de la misma se basa en modelos de desarrollo económico que buscan ganancias a expensas del medio natural y social. En este contexto, existe el modelo de desarrollo sostenible, que requiere una acción mundial para reformular el modelo de conjunto de la sociedad industrial, lo que permite armonizar la relación del hombre con la naturaleza y las relaciones entre los hombres. Hoy, el discurso del medio ambiente si intensificou y se presenta cada vez más importante, especialmente en la formulación de políticas, modelos y teorías sobre el desarrollo, basado en el concepto de desarrollo sostenible. En este trabajo se hace un panorama de la situación de estancamiento causado por la aplicación del modelo de desarrollo sostenible, y un análisis de distintas cuestiones relacionadas con este modelo de desarrollo, que llevan a puntos de vista contradictorios acerca de los "sacrificios" sociales e individuales derivados de una mayor conciencia y el uso equilibrado de los recursos naturales.

Palabras clave: el desarrollo sostenible, medio ambiente, la sociedad contemporánea, la industrialización.

\section{Introdução}

Hoje, o "Sujeito Social" é um poderoso agente capaz de alterar completamente o meio ambiente. Consequientemente, as mudanças ambientais no mundo estão profundamente relacionadas com o comportamento humano. A sociedade contemporânea está se tornando insustentável, devido a inúmeros problemas sócioambientais, dentre eles o crescimento acelerado da população, o esgotamento dos recursos naturais e a poluição do meio ambiente.

Durante muito tempo, acreditou-se que era possível um processo de desenvolvimento com base no uso intensivo dos recursos naturais. Assim, a sociedade 
industrial deu início a grandes avanços tecnológicos, mas, paralelamente, provocando grandes impactos sócio-ambientais. E de todas as civilizações que já existiram na história do homem, nunca nenhuma outra degradou tanto o meio ambiente como a sociedade contemporânea, em virtude dela estar fundamentada em modelos de desenvolvimento econômico de alta tecnologia que visam somente o lucro em detrimento do meio natural e social.

Somente após a II Guerra Mundial, iniciaram-se algumas iniciativas no sentido de se repensar os impactos desse modelo econômico devastador, por exemplo, com a realização de eventos relacionados à reflexão sobre os problemas ambientais. Em particular, as décadas de 1960 e 1970 foram marcadas pela intensificação das discussões a respeito das relações existentes entre meio ambiente e desenvolvimento econômico, por meio de movimentos e eventos bastante significativos do ponto de vista sócioambiental, como a Conferência de Estocolmo. Na década de 1980, surge a concepção de desenvolvimento sustentável, resultado de inúmeros debates e críticas relacionadas aos modelos tradicionais de crescimento econômico. Na década de 1990, houve grande impulso com relação à consciência ambiental na maioria dos países do Globo.

O conceito de desenvolvimento sustentável tem evoluído, desde o seu surgimento, de forma a abranger em si todas as questões que se inter-relacionam com o meio ambiente e o desenvolvimento humano. Porém, também são grandes os conflitos e desafios relacionados à aplicabilidade desse modelo de desenvolvimento, pois, para colocá-lo em prática, é necessário reformular todo o modelo de sociedade industrial. O que provoca opiniões contraditórias acerca dos "sacrifícios" sociais e individuais decorrentes de uma atitude mais consciente em relação ao uso dos recursos naturais

No presente trabalho, será feita uma síntese sobre os impasses provocados pela implantação do modelo de desenvolvimento sustentável, além de uma análise de diferentes questões relacionadas a esse modelo de desenvolvimento. $\mathrm{O}$ desenvolvimento sustentável para muitos, segundo Camargo (2003), é uma utopia, porém observando a forma desenfreada e eminentemente consumista com que a sociedade contemporânea caminha, pode constatar que esse modelo de desenvolvimento pode vir a ser a única opção viável e segura para garantir o futuro da civilização humana.

\section{A evolução da Consciência Ambiental no Século XX}


A preocupação com a questão ecológica ${ }^{1}$ decorrente dos processos de crescimento e desenvolvimento deu-se recentemente, primeiro nos países da Europa e nos Estados Unidos, e apenas muito tempo depois veio a se espalhar pelos países do Terceiro Mundo, como o Brasil. Essa preocupação ocorreu depois de uma gradativa tomada de consciência das pessoas em relação à situação crítica de degradação ambiental $^{2}$, e que hoje mobiliza Organizações Não-Governamentais (ONGs), comunidades, meios de comunicações, escolas e diversos outros setores da sociedade.

Por um longo período, considerava-se que o processo de desenvolvimento era ilimitado, e que os recursos naturais eram infinitos. Por causa dessa ideologia, foi construída uma sociedade industrial com base no uso intensivo dos recursos naturais. Dessa forma, tanto o processo de produção e consumo Capitalista quanto o Socialista tinham por pressuposto a natureza como recurso a ser explorado.

Desde o início da Revolução Industrial, a implantação de técnicas de produção e consumo predatórias vem provocando transformações drásticas no ambiente natural. Somente a partir da II Guerra Mundial é que se verifica, de modo acentuado, uma preocupação com o meio ambiente dentro de uma perspectiva global.

Segundo Barbieri (2003), o Pós-Guerra trouxe inúmeras consequiências negativas para o meio ambiente, devido ao desenvolvimento acelerado que se verificou, principalmente, nas áreas diretamente envolvidas nos conflitos, e também nos países periféricos, que buscam o desenvolvimento industrial também com base no uso intensivo dos recursos naturais.

Os sinais da crise ambiental no período Pós-Guerra agravaram-se, o que levou as autoridades governamentais de todo o mundo a um consenso da necessidade premente de se reverter este quadro, sob pena da destruição de toda a vida no planeta. Logo, as décadas que se seguiram ao Pós-Guerra foram fortemente marcadas pela discussão a respeito do modelo de desenvolvimento e crescimento econômico, predominante desde a Revolução Industrial.

Em 1969, o Governo da Suécia propôs à Organização das Nações Unidas (ONU), a realização de uma conferência internacional para tratar da questão ambiental.

1. De acordo com Reigota (2006, pg.19) "a ecologia é uma ciência que estuda as relações entre os seres vivos e o seu ambiente físico e natural."

2. Reigota (2006, pg.20) alerta que há certa confusão conceitual entre educação ambiental e ecologia. 
Essa proposta só encontrou maior receptividade após o desastre de Minamata, no Japão, que levou à morte de milhares de pessoas contaminadas pelo mercúrio lançado ao mar por empresas locais (Giansanti, 1998). Aceita a proposta, em 1972 foi realizada Conferência da Organização das Nações Unidas para o Meio Ambiente e Desenvolvimento, ou simplesmente "Conferência Estocolmo". A principal preocupação dessa Conferência era conter as várias formas de poluição, sendo que os debates foram marcados por uma polêmica que envolveu, de um lado, os representantes de países centrais e membros da comunidade científica, reunidos no chamado Clube de Roma, que defendia o crescimento zero, e, de outro, representantes de países do Terceiro Mundo, que reivindicavam o direito ao desenvolvimento, mesmo trazendo impactos ambientais. De modo geral, ambos os lados não questionavam o sistema econômico utilizado, apenas buscavam aperfeiçoá-lo, com medidas restritivas localizadas.

A partir da Conferência de Estocolmo, aprofundaram-se os questionamentos sobre o processo de desenvolvimento e a necessidade de se encontrar alternativas viáveis para os impactos ambientais causados pelo sistema atual de desenvolvimento econômico. Nesse contexto, o canadense Maurice Strong em 1973, apresenta o conceito de ecodesenvolvimento, no Programa das Nações Unidas para o Meio Ambiente (PNUMA), visando à relação meio ambiente ${ }^{3}$ e desenvolvimento das zonas rurais dos países subdesenvolvidos. Em seguida, Ignacy Saches reelabora o conteúdo desse conceito, estendendo-o às áreas urbanas, e indicando estratégias plurais e planejadas de harmonização entre as atividades sócio-econômicas dinamizadas e o trabalho de gestão do meio ambiente (Pires, 1998).

A expressão ecodesenvolvimento aos poucos foi sendo substituída por desenvolvimento sustentável, apesar de ainda ser bastante utilizada em vários países europeus, asiáticos e latino-americanos (Sachs 1993, p.2). Já a expressão desenvolvimento sustentável tem origem no documento denominado World Conservation Strategy (Estratégia Mundial para a Conservação), elaborado pela União Internacional para a Conservação da Natureza (UICN), juntamente com PNUMA e o Fundo Mundial para a Natureza (WWF). De acordo com esse documento, a definição de desenvolvimento sustentável refere-se ao processo que melhora as condições de vida das comunidades humanas e, ao mesmo tempo, respeita os limites de carga dos 
ecossistemas (Pires, 1998). Assim, neste conceito de desenvolvimento sustentável (ou sustentabilidade) procuram-se soluções não apenas para os problemas ambientais, mas também para os sociais, políticos e culturais.

Em 1983, foi criada, por intermédio da Assembléia Geral das Nações Unidas, a Comissão Mundial sobre o Meio Ambiente e Desenvolvimento (CMMAD), também conhecida como Comissão de Brundtland, por ter sido presidida pela primeiraministra da Noruega, Gro Harlem Brundtland. O objetivo dessa comissão era reexaminar os problemas críticos do meio ambiente e do desenvolvimento do planeta e formular propostas realistas para solucioná-los (Camargo, 2003).

Em 1987, a Comissão de Brundtland publica o relatório Our Common Future (Nosso Futuro Comum), que ficou conhecido como Relatório Brundtland, obtendo ampla repercussão internacional. Nesse relatório o termo desenvolvimento sustentável passa a ser definido como "[...] aquele desenvolvimento que atende às necessidades do presente sem comprometer as possibilidades das gerações futuras atenderem as suas próprias ${ }^{4}$.

O mérito desse relatório está na identificação das linhas gerais para um diagnóstico da crise social e ambiental em escala global e na valorização de princípios, como a democracia, a igualdade, eqüidade e a justiça social. Porém, é necessário examinar com cuidado os limites desse conceito e as condições econômicas, políticas e sociais existentes para colocar em prática seus princípios (Giansanti, 1998).

No final da década de 1980, podemos destacar também o Plano Verde Canadense, elaborado com intensa participação da sociedade civil para o período 1990 a 1995.

A década de 1990 foi marcada, principalmente, pelo grande impulso com relação à consciência ambiental na maioria dos países. Em 1992, ocorre no Rio de Janeiro a Conferência das Nações Unidas sobre o Meio Ambiente e Desenvolvimento (CNUMAD), também conhecida como Rio-92, ECO-92 ou Cúpula da Terra. Foi considerado o maior evento mundial do século $\mathrm{XX}$ sobre o meio ambiente, no qual foram aprovados cinco documentos oficiais: a Declaração do Rio de Janeiro sobre o

3. Kloetzel (1998, pg.14) afirma que ecologia e meio ambiente de forma alguma são sinônimos. O primeiro conceito seria a "ciência da morada"; o segundo é a própria morada/ecossistema.

4. Comissão Mundial sobre Meio Ambiente e Desenvolvimento. Nosso Futuro Comum (CMMAD), Rio de Janeiro, Fundação Getúlio Vargas, p.46, 1988. 
Meio Ambiente e o Desenvolvimento, com 27 princípios sobre obrigações ambientais e questões de desenvolvimento; a Agenda 21, um cronograma de ação para se implementar o desenvolvimento sustentável; a Convenção sobre Mudanças Climáticas; a Declaração de Princípios sobre Florestas; e a Convenção da Biodiversidade (Barbieri, 1997; Giansanti, 1998).

Para Barbieri (2003), a Rio-92 iniciou um novo ciclo de conferências sobre desenvolvimento e meio ambiente na esfera da ONU, destacando-se entre outras, a Conferência sobre Direitos Humanos (Viena, 1993); a Conferência sobre População e Desenvolvimento (Cairo, 1994); a Conferência sobre Mudança Climática (Berlim, 1995); a Conferência sobre a Mulher (Pequim, 1995) e a Conferência sobre Assentamentos Urbanos (Istambul, 1996). Esse ciclo tem como objetivo implementar os tratados e convenções produzidas pela CNUMAD, bem como aprofundar os temas tratados na Rio-92.

De acordo com Barbieri (2003), muito do que foi tratado na Agenda 21, e em outros documentos aprovados na Rio-92, ainda não foi colocado em prática, devido a muitos chefes de governo apoiarem propostas e acordos internacionais contrários às suas convicções e compromissos partidários, em face às pressões exercidas pela exposição dos temas na mídia internacional e à vigilância ruidosa das ONGs. Portanto, muito pouco foi feito depois para ratificá-los e implementá-los em seus países. Além disso, a Agenda não está completa, porque alguns assuntos importantes não foram tratados com seriedade, entre eles a proibição da produção de armas nucleares.

Em 1997, no Rio de Janeiro, cinco anos após a Rio-92, foi realizado um encontro não-oficial denominado Rio+5, organizado pela entidade "Amigos da Terra", a fim de se avaliar o efetivo andamento das decisões da Agenda 21. De acordo com Pelizzoli (1999), os relatórios tirados a partir do Rio+5 enfatizam, novamente, que é necessário levar a sério a implementação da Agenda 21 e os Conselhos de Desenvolvimento Sustentável em vários níveis, visto a urgência, em especial das políticas públicas, de capacitação e encaminhamento das propostas acordadas nacional e internacionalmente.

Em 1997, é assinado o Protocolo de Kyoto, Japão, um novo componente da Convenção Marco sobre Mudança Climática na Rio-92, que contém, pela primeira vez, 
um acordo que compromete os países desenvolvidos a reduzir suas emissões de gases de efeito estufa em 2000, nos níveis de $1990^{5}$.

Segundo Camargo (2003), outro marco importante da década de 1990 é o fato de diversos grupos do mundo todo estarem engajados, desde a Rio-92, num projeto para que seja criada uma "Carta da Terra", que contempla todas as dimensões do homem em sua interação com a natureza. Finalmente, em março de 2000, na Organização das Nações Unidas para a Educação, a Ciência e a Cultura (Unesco), em Paris, foi aprovada a "Carta da Terra", que foi apresentada e assumida pela ONU em 2002. Baseada em princípios e valores fundamentais, esse documento serve como um código ético planetário, e é equivalente à Declaração Universal dos Direitos Humanos, no que concerne à sustentabilidade, à eqüidade e à justiça social.

Em 2000, é realizada a VI Conferência das Partes Convenção-Quadro das Nações Unidas sobre Mudanças Climáticas (COP6 - 6th Conference of the Parties UNFCCC United Nations Framework Convention on Climate Change), para debater alguns importantes temas do Protocolo de Kyoto, comprometendo vários países desenvolvidos a reduzir suas emissões de gases de efeito estufa para o período de 20082012 em 5,2\% a menos do que em 1990. Mas, para que este Protocolo fosse colocado em vigência, seria necessária a ratificação de, no mínimo, 55 governos, para contabilizar 55\% das emissões de $\mathrm{CO} 2$ produzidas pelos países desenvolvidos. Isso significaria que os Estados Unidos não poderiam bloquear o Protocolo sem o respaldo de outros países.

Em 2002, em Johannesburgo (África do Sul), foi realizada a maior conferência da história da ONU, a "Cúpula Mundial sobre Desenvolvimento Sustentável (Rio+10)", que não obteve o sucesso esperado, por causa dos poucos resultados obtidos em comparação com os recursos e esforços mobilizados pela África do Sul e pelas 191 delegações presentes. Pelo que tudo indicou, o EUA foi o único país satisfeito com o resultado da Rio+10, por não ter ratificado o Protocolo de Kyoto e bloqueado vários acordos dessa conferência.

Finalmente, no dia 16 de fevereiro de 2005, o Protocolo de Kyoto entra em vigor, após a oficialização da ratificação da Rússia. Esse protocolo contou com a 
ratificação de 141 países. Os Estados Unidos não ratificaram o protocolo, alegando que sua adesão estaria comprometendo profundamente o seu crescimento econômico.

Para Camargo (2003), atualmente, o discurso ambiental tem-se intensificado e ganho importância, principalmente, na formulação de políticas, modelos e teorias a respeito de desenvolvimento, apoiado na concepção de desenvolvimento sustentável. Ou seja, o desenvolvimento sustentável é um tema indispensável nas discussões sobre políticas de desenvolvimento que visam sinalizar uma alternativa às teorias e aos modelos tradicionais de desenvolvimento da sociedade contemporânea, desgastados numa série infinita de frustrações ao longo de sua história.

\section{Algumas questões que envolvem o Desenvolvimento Sustentável}

Em toda a história da civilização humana, a sociedade contemporânea foi a que mais interferiu nos ciclos da natureza e alterou os ecossistemas, comprometendo a vida na Terra. Pode-se observar que o processo de desenvolvimento contemporâneo fundamenta-se numa dinâmica crescente e contínua de problemas, como: pobreza, exclusão social, desemprego, chuva ácida, efeito estufa, depleção da camada de ozônio, poluição do ar e da água, lixo tóxico, esgotamento dos recursos naturais nãorenováveis, desertificação etc. $\mathrm{Na}$ verdade, esses problemas, que são globalmente interligados e interdependentes, estão profundamente relacionados ao comportamento humano.

Segundo Pires (1998), os problemas ambientais da atualidade são decorrentes do crescimento econômico, e respaldados em uma ciência e em uma técnica, que privilegiam o lucro em detrimento da preservação, o capital vis-à-vis o trabalho, o econômico em relação ao social, o poder frente à ética. Por isso, talvez, venha ampliando-se paulatinamente o enfoque sociológico sobre as interfaces entre meio ambiente e desenvolvimento.

Nesse contexto, a solução para os problemas ambientais exige uma ação global no sentido de reformular todo modelo de sociedade industrial. E uma proposta de modelo é o de desenvolvimento sustentável, que permite harmonizar a relação do homem com a natureza e as relações dos homens entre si. 
Pires (1998) diz que da forma com é concebido no Relatório Brundtland, desenvolvimento sustentável supõe em acreditar na racionalidade dos agentes econômicos articulados em ações rigorosas de planejamento, que se traduz na ideologia central do modelo de desenvolvimento e das formas de expansão transnacionais do capitalismo em vigor, que tornem compatíveis interesses tão diversos quanto a busca do lucro, a lógica do mercado, a preservação da natureza e até mesmo a justiça social.

Para Rampazzo (1999), a concepção de desenvolvimento sustentável representa, por um lado, a tentativa de buscar o equilíbrio, a harmonia. Por outro, segundo esse autor, há uma preocupante tendência que se torne mais uma "panacéia salvacionista", não conseguindo obter êxito algum. Desta forma, existe uma disputa por conteúdos sobre o modelo de desenvolvimento sustentável, em que alguns agentes sociais pretendem torná-lo complementar ao padrão de desenvolvimento tradicional, enquanto outros pretendem dotá-lo de uma base mais radical, de igualdade, eqüidade e justiça social e de respeito aos limites do ecossistema.

$\mathrm{Na}$ realidade, hoje o mundo caminha por rumos que desafiam qualquer noção de sustentabilidade, apesar de reconhecer a importância da concepção de desenvolvimento sustentável. De acordo com Proops et al. (1997), somente o Estado, enquanto instituição, pode oferecer potencialmente a escala temporal necessária à sustentabilidade, além de possuir a autoridade e os meios potenciais para atuar como um agente de equilíbrio em face dos poderosos grupos de interesse. E para alcançar a sustentabilidade um pré-requisito necessário é um sistema político e econômico estável que permita a participação de toda a sociedade. Para isso, a formulação de uma política para o desenvolvimento sustentável requer examinar em detalhe as diferenças entre a tecnologia, a estrutura de capital, a demanda final e o estado da natureza, tanto no presente quanto em relação à meta operacional. Desta forma, o papel da política será de: assegurar a adequada reestruturação do estoque de capital, abandonar técnicas ultrapassadas e adotar novas técnicas; promover a "renovação" da natureza de modo que permita uma atividade econômica sustentável; mediante a educação e a mudança institucional, adequar os padrões de consumo, tornando-os compatíveis com a tecnologia e com o estado da natureza na meta operacional sustentável.

Ainda para os mesmos autores, há duas tendências que tangem à sustentabilidade nas sociedades ocidentais: no campo da oferta, através de uma 
tendência benéfica de se usar tecnologias e produtos mais "brandos"; e no campo da procura, com uma tendência prejudicial de se consumir cada vez mais. Portanto, para se obter uma política efetiva de sustentabilidade, deve-se influenciar o campo de demanda. Para isso, faz-se necessário o consenso da população.

Segundo Camargo (2003), alguns dos principais empecilhos políticoeconômicos traduzem-se na grande diferença econômica existente entre os países e dentro dos países quanto aos níveis de produção, consumo e renda per capita; o atual estilo de vida consumista; a dificuldade de avaliar o impacto de nossas decisões políticas e econômicas sobre a natureza; as concepções de Produto Nacional Bruto (PNB) e de outros importantes métodos de avaliação do desempenho econômico de um país que são desvinculados das questões ambientais; projetos de desenvolvimento mal orientados; os interesses político-econômicos individuais das grandes potências e corporações; a falta de comprometimento e de responsabilidade social de instituições públicas e privadas; má distribuição de renda.

Além disso, com a intensificação e importância que o discurso de sustentabilidade tem ganhado nos últimos tempos, vários segmentos políticos e sociais estão usando deste discurso para servir de outros propósitos, atendendo seus próprios interesses. E isto é um problema que tem sido muito debatido por vários estudiosos, pois está levando a distorção, ou a perda do verdadeiro objetivo do desenvolvimento sustentável.

Diante de tantos empecilhos, observa-se que existem interesses conflitantes em todos os níveis do desenvolvimento sustentável, e que podem estar diretamente ou não relacionados tanto aos custos do controle da poluição, aos efeitos globais de determinadas formas de desenvolvimento econômico ou dos próprios modelos de produção e consumo utilizados.

Becker (1999) comenta que o desenvolvimento sustentável, enquanto projeto alternativo de desenvolvimento humano, não é um dado de fato, mas um ideal a ser perseguido; não é uma existência, mas um valor; não é um ser, mas um dever ser. Além disso, o que movimenta a humanidade e dá direção ao processo de desenvolvimento humano são as necessidades e os desejos humanos, sendo estas últimas consideradas como fator existencial de maior relevância. Becker (1999) ressalta ainda que, as relações dos homens com a natureza, as relações dos homens entre si e as 
relações de poder dão forma e conteúdo a cada espaço, e a um determinado e específico processo de desenvolvimento. Assim, estruturam, a cada tempo histórico, uma determinada organização econômica, social e política possível e/ou indispensável para produzir as necessidades e os desejos de cada grupo social.

Vivemos num período de transição, em que se revela nas múltiplas dimensões de uma crise decorrente do esgotamento do modelo de desenvolvimento tradicional e se pré-anuncia na emergência do desenvolvimento sustentável.

As dificuldades $\mathrm{e}$ as premissas do processo de transição para o desenvolvimento sustentável são analisadas por vários autores. Sachs (1994), por exemplo, indica quatro premissas básicas nesse processo de transição que são: ter a duração de várias décadas; os países industrializados deverão assumir uma parte proporcional nos custos de transição e nos ajustes tecnológicos; estimular a capacidade institucional para redirecionar o processo tecnológico; além de mudanças efetivas no estilo de vida da sociedade, de um modo geral, e de cada indivíduo, de modo particular.

Nesse momento de transição, é preciso, desde já, que a sociedade toda trabalhe alternativas viáveis e transitórias, como desenvolver e adotar tecnologias e métodos mais eficazes de administrar os recursos ambientais, e que ajudam, pelo menos, a minimizar os impactos ambientais, antes que seja tarde de mais.

Conforme Ribemboim (1997) afirma que o redirecionamento do setor energético para uma maior utilização de alternativas limpas e renováveis é condição básica para o desenvolvimento sustentável, e encontra-se estreitamente relacionado com tecnologias limpas, poluição, efeito estufa, mudanças climáticas, chuva ácida, etc. Para isso, deve-se estimular a busca de fontes alternativas de energia renováveis que diminuam a incidência de impactos ambientais. Entre elas destacamos: o álcool etílico (extraído da cana-de-açúcar, mandioca e milho); energia solar, obtida a partir da transformação da luminosidade em energia elétrica; energia eólica, que movimenta moinhos de vento para bombear água para sistema de irrigação e para animais.

No setor agrícola, diversos autores ressaltam que a consolidação da prática da agricultura sustentável dependerá da busca de soluções específicas de acordo à realidade de cada ecossistema, mas é possível neste momento de transição tomar algumas medidas, tais como: rotação de cultura; integração da produção animal e 
vegetal; fertilização orgânica e verde; técnicas de plantio e trabalho da terra, valorizando os processos biológicos; controle manual de ervas daninhas, etc.

No mercado econômico, a oferta de bens ambientais está ficando cada vez mais escassa e com o aumento de sua demanda, consequentemente tem provocado um aumento significativo nos preços desses bens, passando a ser bastante atraentes e lucrativos. Desta forma, segundo Proops et al (1997), surgem novas oportunidades de negócios, ecobusiness, e os setores produtivos passaram a incorporar a variável ambiental como o seu principal produto. Assim, as empresas buscam novas tecnologias (tecnologias limpas) para garantir a continuidade dos processos produtivos. Essas tecnologias são utilizadas para reduzir o uso de metais pesados e produtos não biodegradáveis; diminuir a emissão de produtos poluentes no ar; reciclar materiais; e diminuir o desperdício.

As empresas que adotam tecnologias limpas têm, entre outros benefícios, a redução dos riscos e acidentes de trabalho, a prevenção da poluição, a diminuição dos gastos de energia, e a fabricação de produtos "verdes" (não agressivos ao meio ambiente), além de receberem um certificado, para que seus produtos sejam aceitos no mercado mundial. Este certificado acaba sendo um "marketing", valorizado as empresas que o adquirirem. Porém, são poucas as empresas que recebem este certificado, pois a utilização de tecnologias limpas, geralmente, envolve investimentos financeiros muito altos, que, conseqüentemente, excluem países pobres e pequenas empresas da competividade global.

Nesse contexto, e após a análise de diferentes questões relacionadas ao desenvolvimento sustentável, há ainda algo a se pensar: Deve-se pagar para preservar o meio ambiente? Tendo em vista que o desenvolvimento econômico da sociedade contemporânea fundamenta-se na produção e consumo de bens, o repasse de custos à sociedade para preservação ambiental poderia, por um lado, aumentar os níveis de exclusão e desigualdade no acesso aos bens produzidos pelo "mercado verde", principalmente às populações dos países pobres. Porém, por outro lado, estaria estimulando a adoção de tecnologias limpas, que visam a reduzir os problemas ambientais causados pela produção e consumo.

Alguns autores consideram que com o aumento da demanda dos produtos "verdes", tenderá a tornar a comercialização mais eficiente e pressionará a redução 
destes custos, possibilitando uma massificação do consumo. Enquanto, outros acreditam que existe uma tendência de que o custo cobrado para preservar o meio ambiente poderá ser, apenas, mais uma forma do sistema capitalista atrair as pessoas a consumir cada vez mais e obter mais lucro, gerando praticamente os mesmos problemas, que promoveram em parte a atual crise sócio-ambiental.

Se pensarmos que cada indivíduo, dependendo do momento de sua vida, do sexo, da idade, de suas aptidões naturais, de sua posição social, de nível de instrução, de sua classe social tem necessidades diferenciadas, fica difícil chegarmos a um consenso acerca do que seria uma ação justa em relação ao uso dos bens naturais, na medida em que, visto sob esse ângulo, cada homem estaria preocupado com seu bemestar, não se importando com as conseqüências de seus atos para os demais.

O dilema contemporâneo baseia-se exatamente nesse ponto: como conciliar os interesses individuais com os comuns a todos os indivíduos? $\mathrm{E}$, dentro dessa questão: como preservar e assegurar o uso devido e racional dos recursos naturais, para que não haja problemas futuros para a humanidade?

Sabe-se que o caminho para uma sociedade menos impactante é um embrulho de difícil solução. Entretanto, nessa conjuntura contemporânea em que vivemos o desenvolvimento sustentável mostra-se como alternativa viável a mudança. Até porque, o fascínio pelo consumo exacerbado na sociedade capitalista é sem dúvida, um "vilão" substancial nessa relação desigual e combinada entre sociedade e natureza.

Neste contexto, um ponto de partida para esta mudança seria por meio da educação ambiental nas escolas, com o objetivo de formar indivíduos mais conscientes. Esta idéia vai de encontro a Grün (2005) quando diz que "a educação ambiental surge hoje como uma necessidade quase inesgotável pelo simples fato de que não existe ambiente na educação moderna. Tudo se passa como se fôssemos educados e educássemos fora de um ambiente”. Portanto, como já foi dito, a sociedade contemporânea vem perdendo a capacidade de interagir com o meio ambiente.

\section{Considerações Finais}

Ao longo desse texto vislumbramos contextualizar o desenvolvimento sustentável a partir de uma perspectiva histórica e social. Esse problema de 
desequilíbrio entre sociedade e natureza intensificou-se com as revoluções industriais que proporcionaram surgimento e adoção de novas técnicas e tecnologias em apropriarse do meio ambiente ${ }^{6}$.

Portanto, faz-se necessário uma análise de diferentes questões relacionadas ao desenvolvimento sustentável, porque a forma como a sociedade contemporânea vem administrando os recursos naturais globais preocupa a humanidade.

Desse modo, o modo de produção capitalista ou modo de gerar a sobrevivência humana está em desequilíbrio. É necessário repensar o tempo e o campo de forças desigual nessa relação dialética entre a sociedade e o planeta Terra. É nítido, que há um descompasso de interesses dessa processualidade socioambiental, a humanidade está acordando que a destruição do meio ambiente, é a reboque a extinção de um futuro equilibrado para as próximas gerações. É bom salientar que Ab'Sáber (2006, pg.28-29) nos dá uma dica quando diz acerca de impactos ambientais:

“(...) Por justificada precaução, vale saber os limites e as possibilidades de acerto do trabalho técnico e científico de prever impactos. Trata-se de refletir sobre um quadro complexo de conseqüências em cadeia que podem resultar de um projeto a ser implantado em determinada região e em um certo sítio. É preciso ter em vista o cenário preexistente de ocupação espacial e qualidade ambiental, assim como os possíveis cenários a serem criados em diferentes profundidades de tempos futuros. Os limites desses tempos não podem ultrapassar o curto e o médio prazo; porque senão seria um puro exercício de adivinhação, subjetivo e irreal. $\mathrm{O}$ estabelecimento desse quadro de possíveis conseqüências depende de uma minuciosa revisão de todos os campos de interferências que ele possa ter com o meio físico, ecológico e social... Acima de tudo, está em jogo uma avaliação de sua viabilidade econômica e técnica, cruzada com a viabilidade ambiental..."

A questão ambiental nos últimos cinqüenta anos sempre foi colocada em pauta de debate, pois o homem sobrecarregou as suas necessidades materiais na produção de objetos e isso gera impactos no meio ambiente, e, conseqüências irreversíveis na totalidade dos ecossistemas. Em resumo, podemos afirmar que os sujeitos sociais e seu comportamento consumista criaram um modelo econômico e de sociedade que caminha para a degradação máxima e insustentável dos recursos naturais do mundo.

Dessa maneira, tentarmos mostrar que apenas a conscientização das pessoas, atitudes ecológicas, educação ambiental, desenvolvimento sustentável é um caminho 
viável e sem volta, entretanto, não é suficiente para mudar o rumo da exploração do planeta. Precisamos sim, de mais ações que atenuem e transforme a causa da destruição do meio ambiente que é modo de produção contemporâneo.

Existe uma necessidade de uma aproximação do homem e mulher com o meio ambiente, esse afastamento foi intensificado pós-revoluções industriais que proporcionou nas relações de trabalho muitos sujeitos alienados. Preocupou-se de forma soberba em produzir objetos ${ }^{7}$ para consumir, esqueceram de produzir vidas saudáveis. Poluímos nossa casa, nosso planeta em prol de sonho mirabolante criar sempre uma nova necessidade no consumir uma mercadoria. A natureza como os homens/mulheres precisam de um tempo para repor suas energias, fazer ajustes. Entretanto, esse tempo não está sendo dado aos rios, ao ar que respirarmos, aos animais, as florestas, aos solos.

Concluindo, nosso maior objetivo de vida é cuidar da nossa morada/o planeta Terra. É importante começar o movimento de transformação socioambiental pelo nosso quarto, casa, rua, lugar, região, paisagem e espaço. Cada indivíduo é ao mesmo tempo fluxo e um nó dentro da rede do ecossistema, portanto, se mudarmos de direção a conseqüência mais obvia é um mundo mais equilibrado. Assim, para começar este movimento de transformação é necessário que cada indivíduo seja reeducado para preservar e assegurar o uso devido e racional dos recursos naturais.

É importante ressaltar que a educação ambiental é um processo que deve ocorrer em todos os indivíduos, melhorando sua relação socioambiental. De acordo com Bispo (2005, pg.146) "a educação ambiental não é uma educação qualquer, muito menos uma educação para alguma coisa específica. É uma identidade que necessita ser constantemente repensada e avaliada, para que não caia no modismo, nem permaneça estática em um mundo tão dinâmico". Desta forma, a educação ambiental é um processo dinâmico que se incorpora dentro da totalidade do movimento da sociedade, nas quais as relações socioambientais são complexas. Esta complexidade ocorre devido à existência inúmeras interações entre fenômenos naturais, culturais e sociais em cada momento histórico.

7. Ver em Santos (1996) o conceito de espaço. 


\section{Referências}

AB'SÁBER, Aziz Nacib. Bases conceptuais e papel do conhecimento na previsão de impactos. In: Previsão de Impactos: O estudo de Impacto Ambiental no Leste, Oeste e Sul. Experiências no Brasil, na Rússia e na Alemanha. São Paulo: Editora da Universidade de São Paulo, 2006.

BARBIERE, José Carlos. Desenvolvimento e meio ambiente: as estratégias de mudanças da agenda 21. 6 . ed. Petrópolis: editora Vozes, 2003.

BECKER, Dinizar Fermiano. Sustentabilidade: Um novo (velho) paradigma de desenvolvimento regional. In: BECKER, D. F. et al. Desenvolvimento Sustentável: Necessidade e/ou Possibilidade?. Santa Cruz do Sul: Editora EDUNIC, 1999.

BISPO, Marciléia Oliveira. Educação ambiental e meio ambiente: as representaçõesd@s professor@s e estudantes do ensino fundamental de CristalândiaTocantins. Goiânia: UFG, 2005 [Dissertação de Mestrado].

CAMARGO, Ana Luiza de Brasil. Desenvolvimento Sustentável: Dimensões e desafios. Campinas: editora Papirus, 2003.

FOLHA ONLINE CIÊNCIA. Fracasso da Rio +10 ameaça realização de outras cúpulas ambientais. <www1.folha.uol.com.br/folha/ciencia/ult306u7152.shtml >. Acessado em: 25 de julho de 2005.

GIANSANTI, Roberto. O Desafio do Desenvolvimento Sustentável. 4. ed. São Paulo: editora Atual, 1998.

GREENPEACE. Clima. Campanha Energia: Do que trata o Protocolo de Kyoto. $\langle$ www.greenpeace.org.br/clima/pdf/protocolo_kyoto.pdf $\rangle$. Acessado em: 25 de julho de 2005.

GRÜN, Mauro. Ética e Educação Ambiental: a conexão necessária. 9a ed. Campinas: Papirus, 2005.

KLOETZEL, Kurt. O que é meio ambiente. São Paulo: Brasiliense, 1998.

MENDONÇA, Francisco. Geografia e meio ambiente. São Paulo: Contexto, 2002.

MINISTÉRIO DA CIÊNCIA E TECNOLOGIA. Convenção sobre Mudanças do Clima. O Brasil e a Convenção-Quadro das Nações Unidas. Protocolo de Quioto. <www.mct.gov.br/upd blob/4193.pdf >. Acessado em: 25 de julho de 2005. 
PELIZZOLI, M. L. A Emergência do Paradigma Ecológico: Reflexões ético-filosóficas para o século XXI. Petrópolis: Editora Vozes, 1999.

PIRES, Mauro Oliveira. A Trajetória do Conceito de Desenvolvimento Sustentável na Transição de Paradigmas. In: DUARTE, L. M. G.; Braga et al. Tristes Cerrados: Sociedade e Biodiversidade. Brasília: Editora Paralelo 15, 1998.

PROOPS, John; FABER, Malte; MANSTETTEN, Reiner; JÖST, Frank. Realizando um Mundo Sustentável e o Papel do Sistema Político na Consecução de uma Economia Sustentável. In: Cavalcanti, C. et al. Meio Ambiente, Desenvolvimento Sustentável e Políticas Públicas. Fundação Joaquim Nabuco-Recife. São Paulo: editora Cortez, 1997.

RAMPAZZO, Sônia Elisete. A Questão Ambiental no Contexto do Desenvolvimento Econômico. In: BECKER, D. F. et al. Desenvolvimento Sustentável: Necessidade e/ou Possibilidade? 2. ed.. Santa Cruz do Sul: editora EDUNIC, 1999.

REIGOTA, Marcos. O que é educação ambiental. São Paulo: Brasiliense, 2006.

RIBEMBOIM, Jacques. Mudando os Padrões de Produção e Consumo. In: RIBEMBOIM, J. (orgs.). Mudando os Padrões de Produção e Consumo. Instituto Brasileiro do Meio Ambiente e dos Recursos Naturais Renováveis: Ministério do Meio Ambiente, dos Recursos Hídricos e da Amazônia Legal. Brasília, 1997.

SACHS, Ignacy. Estratégias de transição para o século XXI: desenvolvimento e meio ambiente. Studio Nobel e FUNDAP, São Paulo, 1993.

SANTOS, Milton. Natureza do Espaço. Técnica e tempo, razão e emoção. $2^{\mathrm{a}}$ edição. São Paulo: HUCITEC, 1996.

Recebido para publicação em junho de 2009 Aprovado para publicação em dezembro de 2009 